\title{
Brazilian Photographic Figure Rating Scale for Men: Psychometric Investigation
}

Perceptual and Motor Skills 2018, Vol. I25(3) 493-506

(C) The Author(s) 2018

Reprints and permissions: sagepub.com/journalsPermissions.nav DOI: $10.1 \mid 77 / 003151251875735$ | journals.sagepub.com/home/pms

@SAGE

\section{Marcela R. de Castro' (D, Fabiane F. R. Morgado², and Ismael F. Freitas Jr. ${ }^{3}$}

\begin{abstract}
As a follow-up to an earlier study from this research group involving women, this study examined the reliability and validity of the Brazilian Photographic Figure Rating Scale for Men (BPFRS-M) for evaluating men's body perception and dissatisfaction. In both versions of the Brazilian Photographic Figure Rating Scale (BPFRS), respondents viewed eight photographic images (seven distorted and one accurate) of themselves in standard poses and then offered self-ratings. In both versions, 10 experts assessed content validity and demonstrated high agreement (defined by ratings of 4-5 on a 5 -point scale) that BPFRS items measured underlying constructs; and experts showed high (>70\%) interrater agreement. For this version, participants were 149 Brazilian men (Mean $=22.4 ; S D=2.7$ years). Pearson correlations demonstrated convergence between the BPFRS-M and two related scales of men's body image. Positive correlations $(p=.000 \mathrm{I})$ were found between actual and respondent-perceived body mass index (BMI). Test-retest and Kappa Index confirmed temporal stability. The BPFRS-M can accurately and reliably assess body perception and dissatisfaction in young men.
\end{abstract}

\section{Keywords}

body image, body dissatisfaction, perception

\footnotetext{
'Department of Physical Education, Federal University of Bahia, Salvador, Brazil

${ }^{2}$ Department of Physical Education, Federal Rural University of Rio de Janeiro, Seropédica, Brazil

${ }^{3}$ Department of Physical Education, São Paulo State University, Presidente Prudent, Brazil

Corresponding Author:

Marcela R. de Castro, Department of Physical Education, Federal University of Bahia, Rua Flórida, 203, apartamento 04, Edifício Parque Universitário, Bairro Graça, Salvador 40150-480, Bahia, Brasil.

Email: marcelarodriguescastro@hotmail.com
} 


\section{Introduction}

The reader is referred to our earlier paper on the development of the Brazilian Photographic Figure Rating Scale (BPFRS) for a review of relevant literature and the rationale for developing this tool (see M. R. Castro, Morgado, \& Freitas, 2017). Although the vast majority of body image research has focused on women, a growing number of studies have turned to male body image, finding that negative attitudes about the body and its appearance are also common in men (Frederick \& Essayli, 2016; Frederick, Sandhu, Morse, \& Swami, 2016; Griffiths et al., 2016), and that men are also susceptible to body image disturbances and associated behavioral dysfunction (Cordes, Vocks, Düsing, Bauer, \& Waldorf, 2016; Dakanalis et al., 2013; Lavender, Brown, \& Murray, 2017; McFarland \& Kaminski, 2009).

Lavender at al. (2017) report that important differences in sociocultural body ideals for men and women have become evident in Western societies. Whereas the ideal for women is a slim body (Laus, Miranda, Almeida, Costa, \& Ferreira, 2012), the social standard for men emphasizes a muscular ideal (Hildebrandt, Langenbucher, \& Schlundt, 2004; McCreary, 2011). Murray, Griffiths, and Mond (2016) see this ideal as central to the relationship between body dissatisfaction and male eating disorder behavior, including efforts to increase muscle mass through the use of steroids (Murray, Griffiths, Mond, Keand, \& Blashill, 2016), overexercise (Dakanalis et al., 2013), and unhealthy dieting (Cafri et al., 2005).

Excessive emphasis on muscularity is a basis of body dysmorphic disorder (Phillips, 2011) that exposes men to risk for harming social, professional, emotional, and psychological health (Murray, Griffiths, Mond, Keand et al., 2016), through depression, negative affect, and social physique anxiety (McCreary, 2011), poor quality of life and higher lifetime rates of suicide attempts (Phillips, 2011), and poorer sexual self-efficacy (Brink et al., 2017). Benford and Swami (2014) and Allen and Walter (2016) found significant positive relationships between a drive for muscularity and (a) neuroticism and (b) lower body appreciation. Swami et al. (2013) explain that neuroticism negatively impacts body image by increasing anxiety and insecurity over appearance (leading to appearance dissatisfaction) and attenuating positive affect (also reducing positive regard for one's own body).

Given this growing male-centered research, we believed it necessary to extend the BPFRS to men in order to improve upon existing body image scales for men in the same way we did for women (M. R. Castro et al., 2017). We agree with others who advocate appropriate methods for assessing how men perceive, think, and behave with respect to their bodies (Cafri \& Thompson, 2004). Among currently available tools for evaluating body image, the most widely used are Silhouette Scales, which are quick, easy, and inexpensive to apply (Cash, 2011; Gardner \& Brown, 2010a), and, in the Brazilian context, Conti 
et al.'s (2013) masculine version of the Stunkard's Figure Rating Scale (SFRS). Kakeshita, Silva, Zanatta, and Almeida (2009) developed the Brazilian Silhouette Scale for Adults (BSSA) specifically for boys and men; Adami et al. (2012) elaborated and validated the figure rating scale for Brazilian adolescents (boys and girls); and A. P. A. Castro, Damasceno, Miranda, Perrout, and Vianna (2011) designed a tool for male bodybuilders. However, past researchers have described weaknesses with these instruments, including (a) unrealistic images of the human body, (b) unrealistic values of body height and weight for target populations, (c) poorly validated psychometric qualities, (d) a predominant reliance on frontal views of the body (Cohen et al., 2015; Fan, Liu, Wu, \& Dai, 2004; Harris, Bradlyn, Coffman, Gunel, \& Cottrell, 2008; LetosaPorta, Ferrer-García, \& Gutiérrez-Maldonado, 2005; Tovée \& Cornelissen, 2001), and (e) a lack of silhouettes able to assess both perceptions and attitudes simultaneously (Gardner \& Brown, 2010a).

As with the BPFRS for women (M. R. Castro et al., 2017), we again sought to reduce potential errors through an instrument developed from real anthropometric measures. We believe this adds realism and elicits a higher level of engagement from respondents, while providing an accurate assessment of body dissatisfaction and body perception. One of the most commonly used anthropometric measures, Body Mass Index (BMI), has been linked to body dissatisfaction (Adami et al., 2012; Austin, Haines, \& Veugelers, 2009; Conti, Frutuoso, \& Gambardella, 2005; Gardner \& Brown, 2011; Graup et al., 2008; Kakeshita et al., 2009; Laus et al., 2012; Pallan, Hiam, Duda, \& Adab, 2011). Other researchers have also added other anthropometric parameters in their body image evaluation tools (Crossley, Cornelissen, \& Tovée, 2012; Fan, Liu, Wu, \& Dai, 2004), including fat percentage (Corseuil, Pelegrini, Beck, \& Petroski, 2009; Damasceno et al., 2012; Pallan et al., 2011), waist-hip ratio (Graup et al., 2008), and biceps-calf ratio (Sardinha, Oliveira, \& Araújo, 2008). To incorporate a perceptual component, psychophysical data have been added, including functional sensations and perceptions (Gardner \& Brown, 2010b) that permit respondents to express their internally organized perceptual experience in ways that can be systematically analyzed and interpreted (Da Silva \& Ribeiro-Filho, 2006).

Following up on our development of the BPFRS with a sample of 142 Brazilian women (M. R. Castro et al., 2017), we employed the same ecological approach in this study with men. The BPFRS introduced respondents to actual front- and side-view images of their own body, providing personalized reference stimuli from which to rate both body perception and satisfaction/dissatisfaction. As our initial work made this tool available only for female populations in Brazil and there is a specific additional need for instruments for men (Cafri et al., 2005; Campana, Tavares, Swami, \& Silva, 2013; Cohen et al., 2015; Dakanalis et al., 2013), this study was designed to extend the BPFRS to men. 


\section{Method}

\section{Participants}

We sent e-mail invitations to participate in this research to 200 men listed within a university enrolment database, and 150 men accepted. Considering factors that influence body image assessment, such as physical exercise, mood, and anxiety (Cash \& Pruzinsky, 2002; McCabe, Ricciardelli, Sitaram, \& Mikail, 2006), we excluded those who had (a) exercised within three hours before the test, (b) experienced atypical sleep (insomnia or altered sleep) the night before the test, or (c) experienced strong emotion on the day of the test (e.g., bad mood, anxiety, sadness, euphoria, or muscle pain). Each participant was questioned directly on these criteria before taking the test. One participant was excluded for failing to comply with the first exclusion criterion. Thus, the final sample consisted of 149 adult men $(22.4 \pm 2.7$ years; BMI $21.3 \pm 2.8)$. All participants signed a Declaration of Informed Consent, and the study was approved by the Ethics Committee of the Universidade Estadual Paulista, Rio Claro Campus, São Paulo.

\section{Materials and Procedures}

Each participant's body weight and height were measured using, respectively, a Tannita digital platform scale (precision 0.1 kilogram) and a Sanny stadiometer with movable head (precision 1 centimeter). These measurements were used to calculate BMI (ratio of body weight to height-squared). Each participant completed two previously researched instruments for evaluating body image: (a) the BSSA, comprising 15 figures with characteristically Brazilian body shapes, with a test-retest coefficient of correlation between actual and perceived BMI (Kakeshita et al., 2009), and (b) SFRS, the original version of which was designed by Stunkard, Sorensen, and Schlusinger (1983), and returned good concurrent validity in validation with Brazilian men. The SFRS comprises nine silhouettes arranged in order of increasing size on a single card (Conti et al., 2013). On both scales, dissatisfaction is defined by the difference between perceived and desired silhouettes. Nonzero values equated to dissatisfied individuals, so that positive values indicated dissatisfaction with being overweight, and negative values indicated dissatisfaction with being underweight.

In it original form, the BPFRS (M. R. Castro et al., 2017) consisted of eight standardized, photographic images in front and side view of the respondents' own body. Similarly, eight juxtaposed stimuli formed the front and side-view Brazilian Photographic Figure Rating Scale for men (BPFRS-M), individualized for each participant. For this study, we involved male participants in all the same steps as carried out previously for the female version of BPFRS. Briefly, these steps were (a) image capture, (b) construction of stimuli and preparation of tasks, and (c) application of the BPFRS-M. This procedure is described in detail 
in M. R. Castro et al. (2017). The preparation of each individual test - spanning the process described earlier, from calculation of the stimuli, manipulation (distortion) of the images to grouping of the images in ascending order of size- took an average of 30 minutes.

On viewing their photographs within the BPFRS-M, each participant was asked to (a) "Choose the silhouette that best represents your real body," and (b) "Choose the silhouette that best represents the body that you would like to have". Only one choice was allowed for each question (choosing from either a front or side view).

Body dissatisfaction was defined as the ordinal difference between the two silhouettes representing the participant's actual and desired bodies. Similarly, body size and shape perception indices were calculated by subtracting the value of the silhouette perceived as representing the actual body from that of the participant's actual silhouette. Thus, both the body dissatisfaction index and the body perception index can be expressed as units from -7 (seven negative) to +7 (seven positive) or as BMI values from -23.5 (twenty-three-point five negative) to 23.5 (twenty-three-point five positive). In the same way, for both indexes (dissatisfaction and perception), the value corresponding to zero was parameterized to represent body satisfaction and precision in body perception, respectively, and any nonzero number indicated body dissatisfaction and imprecision in body perception, respectively. Positive values indicated dissatisfaction due to excess weight and overestimation of body size, while negative values denoted dissatisfaction due to low weight and underestimation of body size. Application of the rating instrument took about five minutes per participant.

\section{Assessment of the Psychometric Qualities of the BPFRS-M}

As validity and reliability are two fundamental requirements for tools in clinical or research contexts (Cash, 2011; Thompson, 2004), we submitted the BPFRS$\mathrm{M}$ to content validity, convergent validity (by BSSA and SFRS), criterion validity (by BMI), and temporal stability testing, following guidelines from Alexandre \& Coluci (2011) and Pasquali (2003), using methods reported previously for the original BPFRS (see M. R. Castro et al., 2017).

\section{Results}

For content validation, 10 expert judges' scores reflected high approval ratings of the measure's capacity to evaluate body dissatisfaction and perception, and they demonstrated higher interrater agreement than a previously suggested criterion of $70 \%$ (Hair, Black, Babin, \& Anderson, 2009), indicating that the BPFRS-M performed well in evaluating body image. Good convergence was demonstrated, with significant results, between the BPFRS-M and both the 
BSSA $(r(147)=.79 ; p=.0001)$ and the SFRS $(r=.71 ; p=.0001)$, indicating that the BPFRS-M evaluates body dissatisfaction validly in young men. We found a significant positive correlation between this male participant sample's actual and perceived BMIs on the BPFRS-M scale $(r(147)=.86, p=.0001)$, demonstrating correspondence between these variables. On the other hand, the negative correlation found between perceived BMI and body dissatisfaction $(r(147)=-.78, p=.00001)$, demonstrated that these variables were inversely related. Temporal stability between test and retest scores was shown by significant positive correlations for both dissatisfaction $(r(48)=.81, p=.0001)$ and body perception $(r(48)=.79, p=.0001)$. Following the Landis and Koch (1977) interpretation of the Kappa Index, we tested the agreement between test and retest responses and verified that body dissatisfaction was substantial for the BPFRS-M $(\kappa=.61,95 \%$ CI $(.307, .956), p=.00005)$ moderate for the BSSA $(\kappa=.593,95 \%$ CI $(.300, .856), p=.00005)$ and poor for the SFRS $(\kappa=.482,95 \%$ CI $(.200, .662), p=.00005)$. In addition, there was substantial test-retest agreement for the evaluation of body perception through the BPFRS$\mathrm{M}(\kappa=.63 ; 95 \%$ CI $(.321, .981) ; p=.00005)$. Thus, the BPFRS-M showed strong temporal stability.

\section{Discussion}

This study adapted and psychometrically evaluated the BPFRS, first developed for women (M. R. Castro et al., 2017), with a male sample for use of the test with men (BPFRS-M). As with the BPFRS, we gauged these male responses in evaluating their body dissatisfaction and body perception using personalized images of their own bodies. Frederick and Essayli (2016), Frederick et al. (2016), Murray, Griffiths, Mond, Keand et al. (2016), and Griffiths et al. (2016) reported that negative attitudes to body and appearance are common in men, and are associated with body dissatisfaction, eating disorders, and unhealthy behaviors (i.e., use of anabolic steroids, overexercise, etc.), just as in women. Other researchers have noted the high prevalence of negative changes in body image among Brazilian men (Coqueiro, Petroski, Pelegrini, \& Barbosa, 2008; Quadros et al., 2010; Silva, Nahasa, Sousa, Duca, \& Peres, 2011) and their associated increased use of anabolic steroids (Abrahin, Souza, Sousa, Moreira, \& Nascimento, 2013; Santos, Rocha, \& Silva, 2011). Within this context, this study answered a call to refine the methodological apparatus used for evaluating body image among men (McCreary, 2011) and to assess the psychometric qualities of such new tools (Gardner \& Brown, 2011).

In the second stage of the study, criteria validation was supported by correlations between both real and perceived BMI $(r=.86)$. Similar values have been reported by previous studies of men: $r=.86$ in Harris et al. (2008), $r=.74$ to .76 in Conti et al. (2013), and $r=.8$ in Gardner et al. (2009). We agree with Swami, Salem, Frunham, \& Tovée (2008) that this strong correlation provides evidence 
that the BPFRS-M can be used to evaluate both body dissatisfaction and perception in men.

Unlike the female version (BPFRS; M. R. Castro et al., 2017), the BPFRS-M showed a negative correlation between BMI perception and body dissatisfaction $(r=-.78)$, reflecting the greater interest men have shown in gaining muscularity, as has been widely reported in the literature (Stwart et al., 2009), beginning in adolescence (Adami et al., 2012) and especially true among athletes (Urdapilleta, Aspavlo, Masse, \& Docteur, 2010). Silva et al. (2011), in a study of young Brazilian men, found that lower BMI and the presence of common mental disorders (nonpsychotic mental disorders) were associated with body dissatisfaction characterized by weighing less than the ideal (rather than more than the ideal, as has characterized body dissatisfaction among women).

Following our earlier procedures (M. R. Castro et al., 2017), we used two other instruments to ascertain whether the BPFRS-M evaluated the target construct. Convergent validity was demonstrated by correlations between the BPFRS-M and both the BSSA $(r=.79)$ and the SFRS $(r=.71)$. Pulvers et al. (2004), using similar methodology, showed good convergent validity between their instrument and both Williamson's tool and the Stunkard scale $(r=.79$ and .89, respectively). More recently, Stewart, Allen, Han, and Williamson (2009) established convergence between the computerized measure of Body Morph Assessment version 2.0 (BMA 2.0) and Image Assessment for Obesity $(r=.68)$. Swami et al. (2012) found that his computerized measure relying on realistic images, the Photographic Figure Rating Scale, showed associations with body appreciation, internalization of media messages on appearance, and selfreported BMI in groups of women. Of these factors, we tested only the latter in this study, meaning that future studies might address these remaining factors for both male and female versions of the BPFRS.

The BPFRS-M assessed body dissatisfaction in a manner similar to the PFRS (Swami et al., 2008, 2012; Swami, Taylor, \& Carvalho, 2011), and it also performed well in assessing body image perception. This tool improves and refines current methods of body image assessment in men's body image research, in that it uses photographs of the respondent's own bodies for rating stimuli, and it introduces side-view profile stimuli. Cohen et al. (2015) reported that most body size scales rely on a front view only, and they offered various reasons for including the side view with which we agree: (a) While the side view reflects morphological criteria more effectively, the front view also significantly captures body shape variation related to all morphological criteria; (b) both views provide information about the traits underlying body shape and, while some of the information furnished by both views may be redundant, it is also likely that other information can be extracted better from separate angles; (c) as assessed by several health and nutritional status-related bio-anthropometrics, variation in body shape was larger for side than for front body outlines; and (d) the side view can best reflect body shape variations by 
ethno-linguistic group. Thus, we believe this more individualized and realistic measure will improve respondent engagement in the task and yield more accurate and ecologically valid results, with further improvements likely from future research (M. R. Castro et al., 2017).

Swami et al. (2008) and Gardner et al. (2009) point to poor reliability as a common weakness in body image evaluation. In contrast, the BPFRS-M displayed strong test-retest reliability for both body dissatisfaction and body perception ( $r=.81$ and .79 , respectively). Our findings are congruous with those of other studies of similar tools used with men: $r=.77$ in Harris et al. (2008); .84 in Kakeshita et al. (2009); .85 in Gardner et al. (2009); and .86 in Stewart et al. (2009). We have also verified temporal stability in the assessment of male body dissatisfaction $(\kappa=.593)$ and perception $(\kappa=.63)$. Swami et al. (2008) and Gardner and Brown (2010b) suggested that, by assessing these parameters, it is possible to provide effective, secure assessment.

Regarding our study's limitations, our sample was restricted to a particular age group, limiting generalization of these results to other samples. While the 35-day interval between the test and retest may have been quite long, giving different variables not controlled in this study (e.g., changes in exercise or in dietary habits during last 35 days) more time to impact the construct of interest, our test-retest reliability findings were adequate. In addition, some aspects of preparing the methodological apparatus for evaluating the perceptual dimension need to be refined. Just as we had not yet provided normative values in our validation of BPFRS in its original form (M. R. Castro et al., 2017), this lacuna persists with the BPFRS-M. Another important factor in video distortion techniques is that these images lacked three-dimensionality. Rather, images were augmented on the horizontal axis only, which mischaracterizes how human body composition changes naturally. Two parameters relevant to male groups were not addressed here: (a) the BPFRS-M does not distinguish fat and muscle body image components that are important when assessing body image in men, because the "ideal" male body has become increasingly muscular (Blashill, 2011; McCreary, 2011; Murray, Griffiths, Mond, Keand et al., 2016); and (b) we did not follow Blashill's (2011) recommendation that more attention should be paid to the manner in which masculinity and body/muscle dissatisfaction are operationalized. Last, as with the BPFRS for women, our method of evaluation required respondents to be photographed (perhaps an aversive event for some subjects). This led to a lengthier test, a need for additional equipment, and an involved process for generating and displaying distorted images.

These data have important theoretical and practical implications. In Brazil, the BPFRS-M replaces tools developed for and used with other populations whose physical and cultural characteristics differ. In addition, it is now possible to compare men and women on the BPFRS. Measurements with standardized images are apt to be error-prone because of some difficulty individuals 
experience in recognizing themselves in other's body shapes. Also, in practical terms, this study offers an applicable and affordable methodology that can be incorporated into intervention work. The BPFRS-M can enhance the evaluation, diagnosis, and prophylaxis of body dissatisfaction and body perception distortion in males. Moreover, as the BPFRS-M respects and includes participants' individual characteristics, it is well suited to repeated periodic evaluations of the same participant.

\section{Declaration of Conflicting Interests}

The author(s) declared no potential conflict of interest with respect to the research, authorship, and/or publication of the article.

\section{Funding}

The author(s) received no financial support for the research, authorship, and/or publication of the article.

\section{ORCID iD}

Marcela R. de Castro (D) http://orcid.org/0000-0003-3771-1386

\section{References}

Abrahin, O. S. C., Souza, N. S. F., Sousa, E. C., Moreira, J. K. R., \& Nascimento, V. C. (2013). Prevalência do uso e conhecimento de esteroides anabolizantes androgênicos por estudantes e professores de educação física que atuam em academias de ginástica [Prevalence of the use and knowledge of androgenic anabolic steroids by students and teachers of physical education who work in gyms]. Revista Brasileira de Medicina do Esporte, 19(1), 27-30.

Adami, F., Frainer, D. E. S., Almeida, F. S., Abreu, L. C., Valenti, V. E., Demarzo, M. M. P.,... Oliveira, F. R. (2012). Construct validity of a figure rating scale for Brazilian adolescents. Nutrition Journal, 11(24), 2-6.

Alexandre, N. M. C., \& Coluci, M. Z. O. (2011). Content validity in the development and adaptation processes of measurement instruments. Ciência \& Saúde Coletiva, 16(7), 3061-3068.

Allen, M. S., \& Walter, E. E. (2016). Personality and body image: A systematic review. Body Image, 19, 79-88.

Austin, S. B., Haines, J., \& Veugelers, P. J. (2009). Body satisfaction and body weight: Gender differences and iluetaseraphic determinants. BMC Public Health, 9, 313.

Benford, K., \& Swami, V. (2014). Body image and personality among British men: Associations between the big five personality domains, drive for muscularity, and body appreciation. Body Image, 11, 454-457.

Blashill, A. J. (2011). Gender roles, eating pathology, and body dissatisfaction in men: A meta-analysis. Body Image, 8, 1-11.

Brink, F. V. D., Vollmann, M., Sternheim, L. C., Berkhout, L. J., Zomerdijk, R. A., \& Woertman, L. (2017). Negative body attitudes and sexual dissatisfaction in men: The 
mediating role of body self-consciousness during physical intimacy. Archives of Sexual Behavior, 1-9.

Cafri, G., \& Thompson, J. K. (2004). Measuring male body image: A review of the current methodology. Psychology of Men and Masculinity, 5, 18-29.

Cafri, G., Thompson, J. K., Ricciardelli, L., McCabe, M., Smolak, L., \& Yesalis, C. (2005). Pursuit of the muscular ideal: Physical and psychological consequences and putative risk factors. Clinical Psychology Review, 25(2), 125-39.

Campana, A. N. N. B., Tavares, M. C. G. C. F., Swami, V., \& Silva, D. (2013). An Examination of the psychometric properties of Brazilian Portuguese translations of the drive for muscularity scale, the Swansea Muscularity Attitudes Questionnaire, and the masculine body ideal distress scale. Psychology of Men \& Masculinity, 14(4), 376-388.

Cash, T. F. (2011). Crucial considerations in the assessment of body image. In T. Cash \& L. Smolak (Eds.), Body image: A handbook of science, practice, and prevention (2nd ed., pp. 129-137). New York, NY: The Guilford Press.

Cash, T. F., \& Pruzinsky, T. (2002). Future challenges for body image theory, research and clinical practice. In T. Cash \& T. Pruzinsky (Eds.), Body image: A handbook of theory, research \& clinical practice (pp. 509-517). New York, NY: Guilford Press.

Castro, A. P. A., Damasceno, V. O., Miranda, J. A., Perrout, J. R., \& Vianna, J. M. (2011). Photo silhouettes for assessment of body image of bodybuilders. Revista Brasileira de Medicina do Esporte, 17(4), 250-253.

Castro, M. R., Morgado, F. F. R., \& Freitas, I., Jr. (2017). Brazilian Photographic Figure Rating Scale: Development and psychometric investigation. Perceptual and Motor Skills, 124(1), 131-144.

Cohen, E., Ndao, A., Boëtsch, G., Gueye, L., Pasquet, P., Holdsworth, M., \& Courtiol, A. (2015). The relevance of the side-view in body image scales for public health: An example from two African populations. BMC Public Health, 15, 1169.

Conti, M. A., Frutuoso, M. F. P., \& Gambardella, A. M. D. (2005). Obesity and body dissatisfaction amongst adolescents. Revista de Nutrição, 18(4), 491-497.

Conti, M. A., Ferreira, M. E. C., Carvalho, P. H. B., Kotait, M. S., Paulino, E. S., Costa, L. S., ... Scagliusi, F. B. (2013). Stunkard figure rating scale for Brazilian men. Eating and Weight Disorders, 18(3), 317-322.

Coqueiro, R. S., Petroski, E. L., Pelegrini, A., \& Barbosa, A. R. (2008). Body image dissatisfaction: Comparative evaluation of the association with nutritional status in university students. Revista de Psiquiatria do Rio Grande do Sul, 30(1), 31-38.

Cordes, M., Vocks, S., Düsing, R., Bauer, A., \& Waldorf, M. (2016). Male body image and visual attention towards oneself and other men. Psychology of Men \& Masculinity, 17(3), 243-254.

Corseuil, M. W., Pelegrini, A., Beck, C., \& Petroski, E. L. (2009). The prevalence of body image dissatisfaction and its association with unhealthy nutritional status in adolescents. Revista da Educação Física, 20(1), 25-31.

Crossley, K. L., Cornelissen, P. L., \& Tovée, M. J. (2012). What is an attractive body? Using an interactive $3 \mathrm{D}$ program to create the ideal body for you and your partner. Plos One, 7(11), e50601. 
Da Silva, J. A., \& Ribeiro-Filho, N. P. (2006). Avaliação e Mensuração da dor: pesquisa, teoria e prática [Pain evaluation and measurement: Research, theory and practice]. Ribeirão Preto, Brazil: FUNPEP Editora.

Dakanalis, A., Timko, A., Madeddu, F., Volpato, C., Clerici, M., Riva, G., \& Zanetti, A. M. (2013). Are the male body dissatisfaction and drive for muscularity scales reliable and valid instruments? Journal of Health Psychology, 20(1), 48-59.

Damasceno, V. O., Vianna, J. M., Novaes, J. S., Lima, J. P., Fernandes, H. M., \& Reis, V. M. (2012). Relationship between anthropometric variables and body image dissatisfaction among fitness center users. Revista de Psicología del Deporte, 20(2), 367-382.

Fan, J., Liu, F., Wu, J., \& Dai, W. (2004). Visual perception of female physical attractiveness. Proceedings of the Royal Society Biological Science, 271(1537), 347-352.

Frederick, D. A., \& Essayli, J. H. (2016). Male body image: The roles of sexual orientation and body mass index across five national U.S. studies. Psychology of Men and Masculinity, 17, 336-351.

Frederick, D. A., Sandhu, G., Morse, P. J., \& Swami, V. (2016). Correlates of appearance and weight satisfaction in a U.S. national sample: Personality, attachment style, television viewing, self-esteem, and life satisfaction. Body Image, 17, 191-203.

Gardner, R. M., \& Brown, D. L. (2010a). Body image assessment: A review of figural drawing scales. Personality and Individual Differences, 48(2), 107-111.

Gardner, R. M., \& Brown, D. L. (2010b). Comparison of video distortion and figural drawing scale for measuring and predicting body image dissatisfaction and distortion. Personality and Individual Differences, 49(7), 794-798.

Gardner, R. M., \& Brown, D. L. (2011). Method of presentation and sex differences when using a revised figural drawing scale to measure body size estimation and dissatisfaction. Perceptual and Motor Skills, 113(3), 739-750.

Gardner, R. M., Jappe, L. M., \& Gardner, L. (2009). Development and validation of a new figural drawing scale for body-image assessment: The BIAS-BD. Journal of Clinical Psychology, 65, 113-122.

Graup, S., Pereira, E. F., Lopes, A. S., Araújo, V. C., Legnani, R. F. S., \& Borgatto, A. F. (2008). Association between body image dissatisfaction and anthropometric indicators in adolescents. Revista Brasileira de Educacão Física e Esporte, 22(2), 129-138.

Griffiths, S., Hay, P., Mitchison, D., Mond, J. M., McLean, S. A., Rodgers, B.,... Paxton, S. J. (2016). Sex differences in the relationships between body dissatisfaction, quality of life and psychological distress. Australian and New Zealand Journal of Public Health, 40, 518-522.

Hair, J. F., Jr., Black, W. C., Babin, B. J., \& Anderson, R. E. (2009). Multivariate data analysis (7th ed.). Upper Saddle River, NJ: Prentice Hall.

Harris, C. V., Bradlyn, A. S., Coffman, J., Gunel, E., \& Cottrell, L. (2008). BMI-based body size guides for women and men: Development and validation of a novel pictorial method to assess weight-related concepts. International Journal of Obesity, 32, 336-42.

Hildebrandt, T., Langenbucher, J., \& Schlundt, D. G. (2004). Muscularity concerns among men: development of attitudinal and perceptual measures. Body Image, 1, 169-181.

Kakeshita, I. S., Silva, A. I. P., Zanatta, D. P., \& Almeida, S. S. (2009). Construção e fidedignidade teste reteste de escalas de silhuetas brasileiras para adultos e crianças 
[Construction and reliability test retest of Brazilian silhouettes scales for adults and children]. Psicologia: Teoria e Pesquisa, 25(2), 263-270.

Landis, J. R., \& Koch, G. G. (1977). The measurement of observer agreement for categorical data. Biometrics, 33, 159-174.

Laus, M. F., Miranda, V. P. N., Almeida, S. S., Costa, T. M. B., \& Ferreira, M. E. C. (2012). Geographic location, sex and nutritional status play an important role in body image concerns among Brazilian adolescents. Journal of Health Psychology, 18(3), 332-338.

Lavender, J. M., Brown, T. A., \& Murray, S. B. (2017). Men, muscles, and eating disorders: An overview of traditional and muscularity-oriented disordered eating. Current Psychiatry Reports, 19(6), 1-7.

Letosa-Porta, A., Ferrer-García, M., \& Gutiérrez-Maldonado, J. (2005). A program for assessing body image disturbance using adjustable partial image distortion. Behavior Research Methods, 37(4), 638-643.

McCabe, M., Ricciardelli, L., Sitaram, G., \& Mikail, K. (2006). Accuracy of body size estimation: Role of biopsychosocial variables. Body Image, 3(2), 163-171.

McCreary, D. R. (2011). Body image and muscularity. In T. Cash \& L. Smolak (Eds.), Body image: A handbook of science, practice, and prevention (pp. 198-205). New York, NY: Guilford Press.

McFarland, M. B., \& Kaminski, P. L. (2009). Men, muscles, and mood: The relationship between self-concept, dysphoria, and body image disturbances. Eating Behaviors, 10, 68-70.

Murray, S. B., Griffiths, S., \& Mond, J. M. (2016). Evolving eating disorder psychopathology: Conceptualising muscularity-oriented disordered eating. The British Journal of Psychiatry, 208(5), 414-415.

Murray, S. B., Griffiths, S., Mond, J. M., Keand, J., \& Blashill, A. J. (2016). Anabolic steroid use and body image psychopathology in men: Delineating between appearanceversus performance-driven motivations. Drug and Alcohol Dependence, 165, 198-202.

Pallan, M. J., Hiam, L. C., Duda, J. L., \& Adab, P. (2011). Body image, body dissatisfaction and weight status in South Asian children: A cross-sectional study. BMC Public Health, 11(9), 10-21.

Pasquali, L. (2003). Psicometria: Teoria dos testes na Psicologia e na Educação [Psychometrics: Test theory in psychology and education]. Petrópolis, Brazil: Vozes.

Phillips, K. A. (2011). Body image and body dysmorphic disorder. In T. Cash \& L. Smolak (Eds.), Body image: A handbook of science, practice, and prevention (pp. 305-313). New York, NY: Guilford Press.

Pulvers, K. M., Lee, R. E., Kaur, H., Mayo, M. S., Fitzgibbon, M. L., Jeffries, S. K., ... Ahluwalia, J. S. (2004). Development of a culturally relevant body image instrument among urban African Americans. Obesity Research, 12, 1641-1651.

Quadros, T. M. B., Gordia, A. P., Martins, C. R., Silva, D. A. S., Ferrari, E., \& Petroski, E. L. (2010). Imagem corporal em universitários: associação com estado nutricional e sexo [Body image in university students: Association with nutritional status and sex]. Motriz. Revista de Educação, 16(1), 78-85.

Santos, A. M., Rocha, M. S. P., \& Silva, M. F. (2011). Illicit use and abuse of anabolicandrogenic steroids among Brazilian bodybuilders. Substance Use \& Misuse, 46, $742-748$. 
Sardinha, A., Oliveira, A., \& Araújo, C. G. S. (2008). Dismorfia muscular: análise comparativa entre um critério antropométrico e um instrumento psicológico [Muscular dysmorphism: Comparative analysis between an anthropometric criterion and a psychological instrument]. Revista Brasileira de Medicina do Esporte, 14(4), 387-392.

Silva, D. A. S., Nahas, M. V., Sousa, T. F., Duca, G. F. D., \& Peres, K. G. (2011). Prevalence and associated factors with body image dissatisfaction among adults in southern Brazil: A population-based study. Body Image, 8, 427-431.

Stewart, T. M., Allen, H. R., Han, H., \& Williamson, D. A. (2009). The development of the Body Morph Assessment version 2.0 (BMA 2.0): Tests of reliability and validity. Body Image, 6, 67-74.

Stunkard, A. J., Sorensen, T., \& Schlusinger, F. (1983). Use of the Danish adoption register for the study of obesity and thinness. In S. S. Kety, L. P. Rowland, R. L. Sidman \& S. W. Matthysse (Eds.), The genetics of neurological and psychiatric disorders (pp. 115-120). New York, NY: Raven.

Swami, V., Taylor, R., \& Carvalho, C. (2011). Body dissatisfaction assessed by the Photographic Figure Rating Scale is associated with sociocultural, personality, and media influences. Scandinavian Journal of Psychology, 52, 57-63.

Swami, V., Salem, N., Furnham, A., \& Tovée, M. J. (2008). Initial examination of the validity and reliability of the female photographic figure rating scale for body image assessment. Personality and Individual Differences, 44(8), 1752-1761.

Swami, V., Tran, U. S., Hoffmann Brooks, L., Kanaan, L., Luesse, E.-M., \& Voracek, M. (2013). Body image and personality: Associations between the Big Five personality factors, actual-ideal weight discrepancy, and body appreciation. Scandinavian Journal of Psychology, 54, 146-151.

Swami, V., Stieger, S., Harris, A. S., Nader, I. W., Pietschnig, J., Voracek, M., .. Tovée, M. J. (2012). Further investigation of the validity and reliability of the photographic figure rating scale for body image assessment. Journal of Personality Assessment, 94(4), 404-409.

Thompson, J. K. (2004). The (mis) measurement of body image: Ten strategies to improve assessment for applied and research purposes. Body Image, 1(1), 7-14.

Tovée, M. J., \& Cornelissen, P. L. (2001). Female and male perceptions of female physical attractiveness in front-view and profile. British Journal of Psychology, 92(2), $391-402$.

Urdapilleta, I., Aspavlo, D., Masse, L., \& Docteur, A. (2010). Use of a picture distortion technique to examine perceptive and ideal body image in male and female competitive swimmers. Psychology of Sport and Exercise, 11(6), 568-573.

\section{Author Biographies}

Marcela R. de Castro is an adjunto professor at Federal University of Bahia (UFBA), Salvador- BA, Brazil, Department of Physical Education, leader of Center for Research on Motricity and Healt. She earned her PhD in Human Motricity of UNESP in 2014. Her research areas are Effect of Physical activity on Health, body image, human motricity, motor behavior and psychometry.

Fabiane F. R. Morgado is an adjunto professor of Federal Rural University of Rio de Janeiro, Seropédica, Rio de Janeiro, Brazil. She received her PhD in Physical Education at the Campinas 
State University, Campinas, São Paulo, Brazil, in 2013. Her research interests include (a) scale development, (b) cross-cultural adaptation, (c) psychometry, and (d) body image.

Ismael F. Freitas Jr. is an associated professor at São Paulo State University (UNESP), Department of Physical Education, Campus of Presidente Prudente. He earned his PhD in Nutrition and Metabolism in Department of General Medicine of UNESP in 2001. He concluded one Pos Doc sabbatical at Auckland University of Technology, Auckland, New Zealand in 2005 and one in National Institunes of Health - NIH, Bethesda, USA in 2013. His research areas are effect of physical activity on Health, particularly on body composition, lipid metabolism, quality of life and body image in obese children and adolescents and also in postmenopausal healthy and breast cancer survivor women. 